\title{
The Exploration of the Curriculum Assessment Model Based on Formative Evaluation
}

\author{
Chen Zhangliang* \\ School of Management Science and Engineering, Shandong \\ Institute of Business and Technology \\ Yantai, 264005, China \\ Chenzhl_yt@126.com
}

\begin{abstract}
The reform of university curriculum assessment plays a guiding role in improving the quality of teaching in a comprehensive way. Reasonable curriculum assessment is the guarantee for cultivating innovative high-quality talents. By analyzing the irrational ways of the traditional assessment methods, this paper combines the formative evaluation and the finality evaluation organically. Based on the years of teaching experience, this paper constructs a system of multiple assessment methods for university curriculum based on the formative evaluation. Finally, this paper puts forward the concrete implementation plan of curriculum assessment reform. Practice has proved that the new assessment system is feasible and worth promoting.
\end{abstract}

Keywords-Curriculum Assessment; Formative Evaluation; Assessment Methods

\section{INTRODUCTION}

Curriculum assessment is the most important part of the teaching process. Although in recent years, with the promotion of teaching reform in Colleges and universities, the improvement of the standard of talent evaluation, the way of curriculum assessment is constantly changing [3], and the workers engaged in education and teaching have also carried out a lot of beneficial attempts. However, the proportion of ordinary results is low, so that students do not pay attention to the normal assessment, but the main energy is put on the final examination, the effect of study will be discounted [4]. In addition, most of the assessment is simply a simple question or write a small paper, students answer the book or download directly from the Internet, the lack of judgment and deep thinking of the problem, more lack of creative thinking excitation process [5], there is a formalization, pass the field, examination results can not truly reflect the value of the assessment of the course.

\author{
Shi Junwei \\ School of Management Science and Engineering, Shandong \\ Institute of Business and Technology \\ Yantai, 264005, China \\ Shijunwei302@126.com
}

\section{PROBLEMS IN CURRICULUM ASSESSMENT IN UNIVERSITIES}

Curriculum assessment is an important link in the process of education and teaching. At present, the common problems in the assessment link of the University have become the bottleneck of the further improvement of the quality of teaching. Promoting the reform of curriculum examination in Colleges and universities has a guiding role in improving the teaching quality in an all-round way. It is imperative to [1]. There are mainly some aspects of university curriculum assessment.

\section{A. Single form of examination}

The traditional examination mode generally adopts the closed book examination method, and the score calculation is based on the usual results plus the final examination results. At ordinary times, performance accounts for $20 \%-30 \%$ of the total results. The final exam results generally account for $70 \%-$ $80 \%$ of the total score, not less than $60 \%$. Because the final results in the total scores are relatively large, the results of the curriculum examination actually determine the students performance in the course examination. This assessment model is easy to lead to students pass through the test before the test, the way to memorize the test, the lack of professional knowledge of the system, can not improve the ability and literacy. This traditional assessment method, which is based on summative assessment and supplemented by formative assessment, has been widely adopted in the evaluation of academic achievements in major universities. This method is easy to cause the problem of "light to the end of the period", and lead to the phenomenon of "not learning well before the test", and neglecting the accumulation and internalization of knowledge. The evaluation results can not objectively reflect the teaching level and the students' ability to [2]. 


\section{B. There is no rule to follow in the evaluation of the grade}

In traditional roll test, students' performance is mainly determined by the final examination results, but not related to the whole semester's learning process. Students' learning autonomy is not strong, usually do not work hard, end of the assault review, short-term memory to deal with the exam, knowledge is difficult to change into practical ability. Teachers usually decide on their composition and scoring methods for their usual grades. At present, the common problem is that there is no objective evaluation standard to be followed in the evaluation of normal performance, it is difficult to guarantee fair and fair, the assessment item is single and one-sided, and the score is subjective and arbitrary. This makes it impossible to reflect students' learning process and learning effect comprehensively and objectively, and lose the effectiveness and significance of normal assessment. At present, college courses are mostly for large classes, with a large number of students. Teachers need to devote a lot of energy and time to the management of normal grades. This will undoubtedly increase the difficulty of teaching management and increase the workload of teaching. If the usual performance is relatively small, and students do not pay attention to the usual score, teachers' investment in energy and time may be very effective. Therefore, teachers may prefer to adopt the usual way of assessing performance in a relatively simple way and low risk.

\section{Rigid examination system}

At present, most colleges and universities have formed a mature system in the standardization of examination propositions, standardization of examination papers, detailed analysis of examination papers, and unification of data archiving, and so on. The educational departments of the school have strict management on examination time, examination form, examination process, examination paper evaluation, and data filing. As to whether the examination content, the type, the difficulty degree, the grading standard and so on are scientific, reasonable and effective, especially whether the examination content can effectively embody the students' ability, quality and innovation can not guarantee the [5].

In the course assessment, it is common for teachers to pay attention to evaluation results only. They do not pay attention to finding problems to improve teaching through examination, but students are only learning for exams, and they do not pay attention to the improvement of comprehensive quality and ability. The form of examination determines the content of the examination, and the examination of the details of the knowledge points can not fully examine the students' ability to master and use knowledge. They can not exercise the students' ability to analyze and solve problems. They restrict the students' initiative and innovation, and lead to the students' learning of scores and the phenomenon of "high scores and low energy".

\section{CONSTRUCTION OF ASSESSMENT MODEL BASED ON FORMATIVE EVALUATION}

The assessment of students in teaching should serve for training the ability to solve practical problems or create products. It is necessary to truly and effectively reflect this ability. Combined with teaching practice, the assessment model based on formative assessment is constructed from the aspects of assessment time, main body and quantification standard.

\section{A. Time discretization of curriculum assessment}

The discretization of examination time is the key to the realization of knowledge, ability and quality. The promotion of knowledge, ability and quality is the accumulation process from quantitative to qualitative change. Through the course of teaching and learning and completing the assessment task, the accumulation of comprehensive quality, professional ability and knowledge is gradually accumulated. Therefore, in order to ensure the gradual improvement of knowledge, ability and literacy, the course assessment model needs to be evaluated and discrete, that is, during the course of study, the evaluation and evaluation of multi node, multi-level and multi direction should be carried out during the course of course study. Through the multi-dimensional examination, the students have a purpose to review the contents of each class. Through the completion of the routine examination and examination of the course, the basic theoretical knowledge of the course is reviewed and the understanding is deepened. By consulting the reference books, the network data and the panel discussion, the expert consultation, and so on, in the day In regular learning, we gradually train students' ability to communicate with others, teamwork and scientific writing. Through the timely completion of examination questions, students' selfmanagement, hardworking and hardworking can be enhanced. Through the learning process, the students can arouse the enthusiasm of the students in the course of the whole course, and guide the students to strengthen the accumulation and cultivation of knowledge, ability and accomplishment, so as to realize the supervision of the learning process.

\section{B. The composition of the subject of pluralistic evaluation}

The assessment of the students' courses has been done by the teachers alone. It is similar to a subordinate relationship. The assessment and evaluation of this "one speech" is contrary to the formative evaluation, and the subject of assessment evaluation should be diversified. In practical operation, different combinations of assessment subjects can be selected according to specific examination contents. For example, ability assessment, curriculum design and group cooperation, the team members know each other more, and the mutual evaluation is more true and reliable; when the group is displayed, the group members participate in each other evaluation; at the same time, they can also evaluate themselves, and the teacher's evaluation, the participation of the multiple evaluation subjects. This has changed the state of teachers' assessment of students' submitted design reports in the past. Other ways, such as scientific research innovation and practical ability, can be evaluated by the instructors or other departments through the students' participation in the discipline competition, the application of innovative entrepreneurship projects, and the 
joining of teachers' scientific research teams. This multi participant evaluation can measure students' development in a more comprehensive and multi-level way, and also help motivate students to learn and improve themselves.

\section{The quantification of the results of the course assessment}

In the mixed teaching mode, based on the multiple teaching theory, the assessment process should be implemented in a whole process, reflecting the integrity of the teaching process and the learning process. The evaluation method can monitor the whole process of students' online and offline learning, pay attention to the control and evaluation of students' learning process, combine formative evaluation with summary evaluation, and make the course examination Nuclear whole process.

\section{1) Formative assessment}

The so-called formative assessment is a phased assessment of the results of the students' course learning, a phased test of the learning goal, a comprehensive assessment of the learning process, an important part of the course assessment, not a total negation of the traditional assessment method, but a succession and development. On the premise of embodying the characteristics of curriculum and teaching mode, how to build a curriculum assessment system that embodies fair competition, mobilizing and maintaining students' enthusiasm for learning and avoiding "one test or success or failure" is the key to the composition and distribution of the evaluation system module.

This course is based on Formative Assessment (60\%), ensuring the importance of students' learning process in teaching. Through formative assessment, curriculum assessment becomes one of the important means of learning behavior to guide and arouse students' participation ability training enthusiasm. The results of the formative assessment are composed of four parts: classroom performance, online learning, group cooperative learning and practice. The proportion of each part and the description of the evaluation are shown in Table 1.

\section{2) Summary evaluation}

The summary evaluation of the course $(40 \%)$, the use of closed examination, the type, and knowledge points are strictly in accordance with the curriculum requirements, the main assessment of the basic concepts, basic principles, basic skills of the students, the contents of the test questions are focused on the ability of the students to use the knowledge to analyze and solve the problems. It changed the way of examining purely theoretical knowledge in the past.

\section{THE PRACTICE OF CURRICULUM ASSESSMENT REFORM}

In recent years, the teachers' team of the major of safety engineering in our university has actively carried out assessment reform in the teaching of multiple courses to promote teaching and promote learning. This "examination" is a diversified assessment. The contents and methods of assessment change from "heavy knowledge" to "knowledge, ability and quality", and the traditional old test concept of "heavy knowledge and light ability", "heavy theory light practice", "emphasis on light operation" and "heavy result light process". Through the examination of students' knowledge, ability and quality, we can evaluate students' learning process and learning effect more comprehensively and objectively. The specific reform measures are as follows:

\section{A. Diversification of curriculum assessment}

The requirements of the professional post to the ability are pluralistic, and the assessment of the students should also be pluralistic. It is not necessary to use a unified assessment model or standard to treat the students' learning effect, but to establish a diversified assessment system and measure the students with different methods and methods.

The diversification of assessment is also reflected in the multi stakeholder participation in evaluation. In addition to teacher evaluation, students should also be given the opportunity to participate in the examination. Students can be evaluated by mutual evaluation and their advantages and disadvantages can be found through self-evaluation. Introduce the industry evaluation, hire the enterprise experts to participate in the assessment process, evaluate the students from the perspective of engineering technicians, introduce the certification examination of the authoritative industry, assess the students according to the requirements of the industry, make the students understand the requirements of the industry as soon as possible, and make the necessary reserve for the future employment.

\section{B. Group cooperative learning and team system assessment}

In order to enable students to experience team cooperation in the course of course learning and to form a learning atmosphere of mutual assistance and mutual learning, the group implement team assessment team system in practice, question and answer, discussion and other links. Group assessment team system refers to each single item of assessment, a group of members will represent the whole group of the assessment task, and the performance of the team will represent the level of the group and score the team. Although the ability of the members in the group is different, each member may be the leading role of an assessment link, so members must help and cooperate with each other and work together to achieve an ideal team score. Team assessment team system improved students' team consciousness and group members' enthusiasm for participating in the task. In order to further help the group form an atmosphere of mutual help, teachers can add details like game rules. For example, the question link in the classroom, the number of students in a large class, the number of students, in one semester, it is difficult for each student to offer the opportunity to speak. After the group system, the teacher asked a student A to ask the 
question, and the answer was determined by the team. If the answer was not good, there was a chance to ask for help. Transfer questions to another student in this group, B, in order to score. The students who have not answered well are all pulled into the list of key questions, and the teachers will choose the students to speak first in order to urge them to learn their attitude and study carefully.

\section{Diversification of assessment forms}

The diversification of course examination forms is a means to realize ability training. Each course supports different knowledge, abilities and accomplishments. In order to complete the assessment of these supporting points, a variety of assessment forms must be adopted to guide the students to improve themselves from knowledge, ability and accomplishment. Different forms of curriculum assessment have their advantages. The form of closed examination has advantages for the knowledge of theorems and formulas which need mechanical memory, and is applicable to the assessment of basic knowledge. The form of questioning in the classroom helps to arouse the enthusiasm of the students in the classroom and guide the students to think positively; the research report applies to the research and exploration of some professional problems and raises the students' knowledge of the professional knowledge. The experimental report can not only urge the students to use the theoretical knowledge to guide the practice actively, but also promote the students to participate in the experimental operation, improve the students' ability to do it, and exercise their ability to find and solve the problems. The investigation report can help students to understand the course. Or the related status of the industry to improve the students' ability to organize and analyze the data. At the same time, the design and distribution of the questionnaire and the process of recycling can exercise students' communication and communication ability. Only using a variety of curriculum assessment forms can the students' professional skills and professional attainment be fully cultivated and exercised in many ways. This is in line with the needs of the training of applied talents, rather than the cultivation of heavy theory light practice, heavy knowledge and light ability and quality.

\section{A variety of innovative addition terms}

Today, emphasizing quality education, we should strengthen the evaluation function of university examination while not blindly weakening the discriminative function of university examination. We encourage students with ability and willingness to expand their abilities by using all kinds of bonus points, especially to encourage students to get points in practice, such as encouraging students to publish papers, apply for patents, let students record experimental microcourses, and invite excellent students to act as assistants and help students with insufficient ability. To provide students with the opportunity to interact with others by using their knowledge and skills, this is an effective way to enhance knowledge understanding and enhance their ability.

\section{CONCLUSION}

The purpose of curriculum assessment is to promote students' mastery of professional knowledge, professional ability and professional quality. Based on the formative evaluation, "people are all fertile", which requires teachers to abandon the standard of measuring students with a ruler, to establish a diversified assessment model which is more consistent with the development of students, to stimulate the enthusiasm of students, improve the style of teaching, and improve the teaching effect and quality of teaching. This also puts forward higher requirements for teachers' knowledge, ability and literacy. It is necessary for teachers to pay more energy and time to better cultivate innovative talents adapted to the social and economic development and the needs of the enterprises.

\section{ACKNOWLEDGMENT}

This research was financially supported by Shandong Natural Science Foundation: Research on enterprise informatization introduction mode and enterprise value increment oriented to supply and demand network (Grant NO. ZR2012GM003), Teaching Reform Project of Shandong Business School: A Study on Hybrid Teaching Model and Evaluation System Based on Application-oriented Talent Cultivation (Grant NO. 1168G201701) and 2016 "CAD Engineering Drawing" of the Project of Blended Teaching Course of Shandong Business School (Grant NO. 04021203).

\section{REFERENCES}

[1] Shi Junwei, Chen Zhangliang and so on. The exploration and practice of the training of applied talents for safety engineering in Colleges and Universities [J]. Coal higher education, 35 (2): 53-56. (In Chinese)

[2] Shi Junwei, Chen Zhangliang and so on. Research and effect evaluation of mixed teaching reform in Colleges and Universities [J]. Educational technology and equipment in China, 2017(16): 114-117. (In Chinese)

[3] Shi Junwei, Chen Zhangliang and so on. The study and evaluation of the teaching reform of the undergraduate course of safety engineering from $\mathrm{CAD}$ engineering drawing $[\mathrm{J}]$. Energy technology and management, 42(1): 20-22. (In Chinese)

[4] Zhao Jingru. Exploration and practice of the reform of curriculum assessment in Colleges and Universities [J] .Education modernization, 2018(9):91-97. (In Chinese)

[5] Yang Jiagui, Wu Ling, Xu Xiaoli. The construction of the curriculum assessment model from the perspective of Multiple Intelligences [J] .Journal of Shaoguan University Education Science, 39 (2):48-51. (In Chinese)

[6] Tao Yizhou, Jin Minli, Chen Chuwen.Practical exploration of curriculum assessment mode based on process evaluation [J] .Forestry Education in China, 36(2):60-63. (In Chinese)

[7] Wu Na, Cao Fengping, Guo Rongchun. Research on curriculum assessment mode based on application oriented talents training [J] .Education and Teaching Forum, 2018(6):168-169. (In Chinese)

[8] Bi Jiantao, Yu Li, Yan Hui Ju. Research on curriculum assessment system based on ability and process $[\mathrm{J}]$.Information management in China, 17(4): 129-132. (In Chinese) 